\title{
COLABORAÇÃO E CONFIANÇA NA FORMAÇÃO DO PROFESSOR DE LÍNGUA ESTRANGEIRA
}

\author{
Andréa Machado de Almeida Mattos \\ Universidade Federal de Minas Gerais
}

Resumo: Este trabalho relata um estudo de caso que teve por objetivo principal fomentar o desenvolvimento da professora participante através da auto-observação e da reflexão em colaboração com a pesquisadora. A natureza colaborativa e nãodiretiva da metodologia usada para a coleta de dados levou à resultados altamente interpretativos. Estes resultados levam a conclusão de que a participante mostrou sinais de conscientização relacionados a vários aspectos de seu próprio desempenho pedagógico e a metodologia usada provou ser apropriada como ferramentapara desenvolvimento da reflexão do professor. Através de uma abordagem não-diretiva (Freeman, 1990), a pesquisadora assumiu o papel de um participante colaborativo. Essa abordagem, baseada numa relação de confiança, foi - conforme se sugere - exatamente o que deu à professora participante a segurança necessária para refletir sobre sua própria atuação na sala de aula e perceber seus próprios problemas e dificuldades. Ao desempenhar o papel de um parceiro mais capacitado (Vygotsky, apud Lantolf \& Appel, 1994) e, portanto, atuando na Zona de Desenvolvimento Proximal (ibid), a pesquisadora forneceu as ferramentas necessárias para o desenvolvimento da participante.

Palavras-Chave: Formação de Professores - Colaboração Confiança - Zona de Desenvolvimento Proximal (ZPD).

Abstract: This paper reports on a case study aimed at fostering the professional development of the participant teacher through selfobservation and reflection in collaboration with the researcher. The non-directive and collaborative nature of the data collection methodology used yielded highly interpretive results. These results lead to the conclusion that the participant has shown signs of awareness in relation to various aspects of her own pedagogical performance and the methodology used has proved to be appropriate as a tool to foster teacher reflection. Through a 
12 Mattos - Colaboração e confiança na formação do professor de língua...

non-directive approach (Freeman, 1990), the researcher assumed the role of a collaborative participant. This approach, based on a relationship of trust, was - as it is suggested - exactly what gave the participant teacher the necessary confidence to reflect on her own classroom performance and notice her own problems and difficulties. As she performed the role of a more capable peer (Vygotsky, apud Lantolf \& Appel, 1994), therefore acting on the Zone of Proximal Development (ibid), the researcher provided the necessary tools for the development of the participant teacher.

Key Words: Teacher Education - Collaboration - Trust - Zone of Proximal Development.

\section{Introdução}

O crescente interesse de pesquisadores brasileiros pelo tema da formação do professor de língua estrangeira (LE) segue uma tendência mundial da Lingüística Aplicada. Este trabalho se alinha com esta tendência e tem por objetivo ampliar a discussão em torno de um assunto que apenas recentemente vem sendo mais intensamente abordado: a relação muitas vezes conturbada entre o pesquisador e o professor participante de uma pesquisa, uma relação que tende a replicar as situações de hierarquia e poder encontradas também na interação entre o professor de LE e seu supervisor.

Neste trabalho, primeiramente, é feito um breve levantamento de alguns estudos sobre tendências e possibilidades para a supervisão de professores, discutindo suas vantagens e possíveis problemas. A seguir, esta discussão é trazida para o campo da relação entre pesquisador e professor pesquisado, já que guarda semelhanças com a anterior. Depois, o contexto e a professora participante da pesquisa aqui relatada são apresentados e, finalmente, os dados são discutidos. A conclusão retoma a discussão anterior e mostra como, através de suas intervenções durante entrevistas de retrospecção, a pesquisadora conseguiu estabelecer, com a professora participante, uma relação de colaboração e confiança que favoreceu o seu desenvolvimento profissional.

\section{O professor na "Berlinda": as pesquisas sobre supervisão do professor de língua estrangeira}

Segundo Freeman (1996a, 2002), o professor somente começou a ocupar espaço nas pesquisas educacionais em meados dos anos 
70. No campo do ensino de língua estrangeira, no entanto, a preocupação com a formação do professor começou a se delinear mais tarde, no final dos anos 80. Nesta época, Freeman (1989:28) propôs que a formação do professor de línguas fosse baseada no próprio ensino, que ele definiu como "um processo de tomada de decisão baseado nos constituintes de conhecimento, habilidade, atitude e consciência"1 ${ }^{1}$. Richards (1990:3), por outro lado, ressaltou a escassez de pesquisas ou teorias que lidassem com "a natureza do ensino de segunda língua per se". Passados quase 20 anos, no entanto, a pesquisa na área de formação do professor de línguas passou por vários caminhos e acompanhou a mudança ocorrida no campo mais geral da pesquisa sobre aprendizagem de LE, passando de um paradigma de valorização do produto do ensino/ aprendizagem para um interesse pela análise mais profunda do processo em si (FREEMAN, 1996a,b e 2002; MULLOCK, 2006).

Dentre os assuntos debatidos, a questão da interação entre o professor-aprendiz e o supervisor, por exemplo, já foi abordada por vários autores, que se preocupam principalmente com os problemas e benefícios que essa interação pode trazer para um professoraprendiz. O próprio Freeman (1990) examina a interação entre o professor-aprendiz e seu supervisor, argumentando que "o professoraprendiz pode ser ajudado a ensinar com mais eficácia a partir do 'input' e das percepções do professor educador" (ibid, p.105). Assim, o autor discute três opções diferentes que permitem a interação entre o professor-aprendiz e seu supervisor. A primeira é a opção diretiva ("directive option"), na qual o supervisor tece comentários sobre a atuação do professor-aprendiz, fazendo propostas concretas de mudanças. A segunda é a opção de alternativas ("alternatives option"), na qual o supervisor oferece um número limitado de alternativas diferentes para lidar com um ponto selecionado da lição dada pelo professor-aprendiz, com o objetivo de desenvolver nele uma "consciência sobre as escolhas presentes ao se decidir o que e como ensinar" (ibid, p.108). Por fim, a opção não-diretiva (nondirective option), na qual o elemento-chave é exatamente a relação entre o professor-aprendiz e o supervisor, criando-se um diálogo que abre espaço para que o professor-aprendiz encontre suas próprias soluções e seja seu próprio árbitro, ao mesmo tempo em que permite que o supervisor participe desse processo, contribuindo

'Tradução minha, assim como todos os outros trechos citados neste trabalho a partir de originais em inglês. 
14 Mattos - Colaboração e confiança na formação do professor de língua...

com sua experiência e conhecimento, sem, contudo, direcionar as conclusões do professor-aprendiz.

Focalizando também a interação na prática de ensino, Gebhard (1990a) faz um estudo etnográfico de sete professores inexperientes, descrevendo as mudanças de comportamento que resultaram da interação entre os participantes da pesquisa (os professoresaprendizes, o professor educador e os alunos). Gebhard conclui que "a interação fornece ao professor-aprendiz chances de falar sobre seu próprio ensino" (p. 124), criando oportunidades para mudança. Em outro artigo, Gebhard (1990b) apresenta e discute seis modelos diferentes de supervisão de professores de inglês como LE. A exemplo de Freeman (1990), a discussão de Gebhard também se baseia no papel do supervisor enquanto educador e no valor da interação enquanto catalizadora do processo de desenvolvimento do professor. O modelo de supervisão diretiva ("directive supervision") é apresentado como exemplo do tipo de supervisão tradicionalmente utilizado por supervisores, embora apresente vários problemas. $\mathrm{Na}$ visão do autor, um desses problemas é que esse modelo tende a provocar no professor-aprendiz, ou professor-supervisionado, um sentimento de inferioridade em relação ao seu supervisor, o que pode diminuir sua auto-estima. Além disso, o papel do supervisor nesse modelo pode representar uma ameaça para o professorsupervisionado, colocando-o numa posição de defesa em relação aos julgamentos feitos pelo supervisor. Para o autor, ao escolher esse tipo de supervisão, o supervisor corre o risco de restringir ou mesmo retardar o progresso de seus supervisionados.

Como alternativa, Gebhard (1990b) discute outros cinco modelos: supervisão alternativa ("alternative supervision"), supervisão nãodiretiva ("non-directive supervision"), supervisão colaborativa ("collaborative supervision"), supervisão criativa ("creative supervision") e supervisão de auto-ajuda ou exploratória ("self-help - explorative supervision"). Os dois primeiros tipos (supervisão alternativa e não-diretiva) são idênticas às opções oferecidas em Freeman (1990). Já na supervisão colaborativa, o supervisor participa ativamente de qualquer decisão a ser tomada juntamente com o professor, sem contudo direcioná-lo. A supervisão criativa, por sua vez, pode ser uma combinação de vánios ou alguns dos outros modelos de supervisão, ou uma tentativa de buscar respostas em outras fontes, como centros de recursos para professores, ou através do uso de esquemas de observação. Por fim, a supervisão de auto-ajuda ou exploratória 
pretende proporcionar "oportunidades tanto para os professores quanto para os supervisores (...) ganharem consciência da sua prática através da observação e da exploração" (GEBHARD, 1990b:163). Ao contrário de outros modelos de supervisão, na supervisão de autoajuda, o professor educador não é visto como uma ajuda para o professor-aprendiz, mas simplesmente como um outro professor um pouco mais experiente, interessado em aprender mais sobre ensino, através de uma abordagem colaborativa e exploratória, e com o objetivo de desenvolver uma consciência maior sobre os processos de ensino, porém sem fazer julgamentos sobre a atuação do professor-observado. Essa atitude, com o tempo, instigaria no professor-aprendiz o desejo de fazer o mesmo.

No Brasil, a preocupação com a formação do professor de língua estrangeira se intensificou a partir do início dos anos 90 . Dentre os pesquisadores que primeiro se interessaram por essa área podemos citar Almeida Filho (1993), Gimenez (1994) e Moita Lopes (1996). Mais recentemente, esse novo campo tem sido chamado de formação continuada do professor de LE (ALMEIDA FILHO, 1997; BAGHIN \& ALVARENGA, 1997; CELANI, 2003, dentre outros), e pretende incluir não apenas os cursos de pós-graduação e atualização realizados por professores em serviço, mas também as atividades em que o professor se engaja solitária e independentemente, com o objetivo de "refletir sobre o próprio trabalho sem o concurso de outrem" (ALMEIDA FILHO, 1997:31). O interesse pelo assunto parece não ter-se esgotado entre os pesquisadores brasileiros, como é possível perceber pelos vários trabalhos compilados em Almeida Filho (1999) e Leffa (2001), além de alguns trabalhos inseridos em coletâneas mais recentes como Freire, Abrahão e Barcelos (2005) e pela recente edição do Primeiro Congresso Latino-Americano sobre Formação de Professores de Línguas, realizado em Florianópolis-SC, em 2006. Nestes vários trabalhos, o tema revela-se multifacetado e extremamente complexo, o que comprova a necessidade de continuação de um debate mais aprofundado.

\section{A relação pesquisador-pesquisado}

Pica (2000) ressalta que, desde que as pesquisas em sala de aula tiveram início, a relação existente entre professores e pesquisadores passou por vários estágios. Contudo, apenas recentemente essa relação passou a ser alvo da preocupação de autores e pesquisadores 
16 Mattos - Colaboração e confiança na formação do professor de língua...

em Lingüística Aplicada. A autora faz uma boa revisão dessa relação, por vezes conturbada, analisando o passado e comentando o presente, além de discutir o interesse mútuo que leva a uma relação de convergência entre esses dois profissionais.

Pica salienta que, a partir dos anos 70, alguns autores começaram a aconselhar os pesquisadores a" aplicar com precaução os resultados de seus estudos a questões de ensino" (ibid, p. 59). A partir daí, os resultados das pesquisas passaram a ser aplicados na sala de aula com maior cuidado. Além disso, os professores passaram a ver as pesquisas como parte da base de conhecimento de sua profissão. Com o passar dos anos, a relação entre professores e pesquisadores evoluiu, chegando a um estágio de colaboração e complementaridade, como veremos a seguir.

Nas pesquisas em que o professor de LE é o foco de interesse, a questão da relação entre professor e pesquisador é de crucial importância, já que, em geral, o professor passa a ser o principal informante da pesquisa. No início, essa relação foi caracterizada por uma aparente assimetria entre os papéis do professorpesquisado e do pesquisador. A princípio, os pesquisadores se restringiam a descrever o comportamento dos professores na sala de aula (FREEMAN, 1996b). À época, o papel do professor enquanto informante das pesquisas era puramente passivo, já que sua contribuição se limitava a permitir que um pesquisador ou observador assistisse a suas aulas (ALLWRIGHT \& BAILEY, 1991; NUNAN, 1989).

Num segundo momento, quando predominam as pesquisas cognitivas (Freeman, 1996b), o professor-informante assume um papel mais ativo à medida que não basta que ele abra as portas de sua sala de aula para o pesquisador ou observador. É preciso também que ele colabore com o pesquisador, fornecendo dados paralelos, como por exemplo seus planos de aula, e participando de entrevistas ou respondendo questionários. No entanto, nesse tipo de pesquisa ainda predomina uma relação assimétrica entre professor e pesquisador, pois ao professor é delegado o papel de informar seus pensamentos, seus objetivos ou suas crenças, mas é o pesquisador quem detém o saber para analisar e julgar essas informações.

A tendência atual das pesquisas sobre o professor de LE, conforme proposto por Freeman (1996b), pretende ampliar o espaço para a voz do professor-informante, dando maior importância a 
suas próprias percepções e interpretações. Nesse tipo de pesquisa, a relação entre professor e pesquisador tende a se equilibrar, pois se reconhece que o pesquisador já não detém a verdade absoluta para a análise dos dados. O objetivo passa a ser, então, que o professorpesquisado torne-se um participante-colaborador em todas as etapas de coleta, análise e interpretação dos dados, e os resultados da pesquisa passam a depender inclusive da sua motivação para realizar análises e interpretações mais profundas e significativas.

Fazendo uma reflexão sobre os papéis exercidos por professores e supervisores, Gimenez (1999a, b) discute a relação existente entre esses dois profissionais, dentro do contexto do Projeto NAP ${ }^{2}$ A preocupação em estabelecer uma relação mais simétrica entre professores e pesquisadores (aqui representados pela pessoa do professor de nível universitário) está presente na obra organizada por Gimenez (1999a), tanto nos artigos de sua autoria quanto nos artigos de seus colaboradores. Ao se ocupar da questão, a autora denuncia a postura até então assumida pelos pesquisadores que a seu ver raramente demonstram humildade em suas relações com o professor. Incluindo-se entre esses pesquisadores, ela diz:

"Tornamo-lo sujeito de nossas pesquisas, objeto de nossas descobertas e pouco freqüentemente nossos companheiros na 'pronúncia' do mundo. Ao contrário, geralmente nos consideramos superiores, seja ao submetê-los ao crivo de nosso aparato teórico, seja ao elaborarmos implicações para o seu agir. Nosso modelo tem sido essencialmente bancário, procurando respostas que nós mesmos diremos, e as quais são avaliadas por nós mesmos." (GIMENEZ, 1999b: 14).

A autora sugere que os pesquisadores tornem a busca pelo conhecimento mais aberta à contribuição do professor, de forma que esse conhecimento deixe de ser visto como hierarquizado e abstrato, o que levaria à construção de uma relação diferenciada com o professor. Reis (1999), por sua vez, sugere que essa relação seja baseada na confiança, e ressalta que o objetivo dos assessores do projeto NAP é "ajudar o professor a se tornar cada vez mais consciente e crítico de sua prática" (REIS, 1999: 37), levando-os a uma possível e almejada autonomia.

A sugestão dessas autoras, então, é que a relação entre professor

${ }^{2} \mathrm{O}$ NAP (Núcleo de Assessoria Pedagógica para Ensino de Línguas) é um projeto da Faculdade de Letras da Universidade Estadual de Londrina, que tem por objetivo capacitar e assessorar professores de línguas do ensino fundamental e médio (Gimenez, 1999a). 
participante e pesquisador deve basear-se na confiança que ambos podem cultivar entre si. Outros autores também consideram a confiança uma questão fundamental entre o pesquisador e seu informante. Gebhard (1990a), por exemplo, sugere que a atitude do pesquisador ou supervisor deve revelar uma postura nãoavaliativa, e que o objetivo não deve ser julgar o professor ou sua maneira de ensinar, o que permite o estabelecimento de uma relação de confiança entre o professor e o pesquisador/supervisor. Já Chamberlin (2000) examinou as percepções de professores préserviço em relação à sua confiança em supervisores e concluiu que "a confiança tem um papel crítico na supervisão que encoraja a reflexão e a percepção de crenças e valores pessoais" (p.653). A autora lembra, porém, que "a confiança é negociada não apenas através do que as pessoas falam, mas também através de como elas falam (...)" (p.669) . $^{3}$.

Almeida Filho (1997), por sua vez, sugere a adoção de conceitos vygotskianos para definir a relação entre o professor em desenvolvimento e seu observador. $\mathrm{O}$ autor argumenta que o professor que deseja desenvolver-se profissionalmente deve estabelecer sua própria agenda de observação, decidir como avaliar aspectos da sua maneira de ensinar e "quais ações adotar para encaminhar quais mudanças e porque" (ibid., p. 34). Essa atitude é chamada de "formação auto-sustentada do professor" e nela o observador assume o papel de "colaborador, tutor esclarecido e experiente no sentido de Vygotsky" (ibid., p. 34). Almeida Filho se refere ao conceito vygotskiano de" parceiro mais experiente" ${ }^{\prime 4}$, isto é, para Vygotsky ${ }^{5}$, o papel da interação no aprendizado do sujeito é fundamental na medida em que ele pode conseguir realizar tarefas cuja complexidade se encontra além do seu nível de desenvolvimento real através da ajuda de uma pessoa mais velha e/ou mais experiente (LANTOLF \& APPEL, 1994; REGO, 1994). Nesse caso, a aprendizagem ocorre dentro daquilo que Vygotsky chamou de Zona de Desenvolvimento Proximal (ZPD), que é

"a distância entre o nível de desenvolvimento real determinado pela capacidade de solução de problemas de

\footnotetext{
${ }^{3}$ Grifo meu.

${ }^{4}$ Tradução minha do termo original "more capable peer".

${ }^{5}$ Vygotsky, na verdade, ocupou-se apenas do estudo dos estágios de desenvolvimento da criança, porém suas idéias têm sido largamente aplicadas ao campo da aprendizagem como um todo.
} 
forma independente-e o nível de desenvolvimento potencial - determinado pela capacidade de desenvolvimento sob a orientação de um adulto ou em colaboração com um parceiro mais competente" (Lantolf \& Appel, 1994, p. 10).

Esse conceito, que envolve uma relação chamada de"scaffolding", ou andaime, tem sido recentemente utilizado nas pesquisas sobre aquisição de LE. A sugestão de Almeida Filho (1997), dentre outros autores, traz o conceito para o campo da formação do professor. Essa idéia, contudo, não é totalmente nova. No campo da relação entre supervisor e professor supervisionado, Freeman (1990) já sugeria que o professor-aprendiz pode beneficiar-se das percepções e comentários do professor-educador, e aprender a ensinar melhor. Wallace (1991) também sugere uma abordagem colaborativa para a supervisão, com o objetivo de desenvolver a autonomia do professor através da reflexão e da auto-avaliação. Mais recentemente, Nyikos e Hashimoto (1997) utilizaram-se do conceito para promover a aprendizagem colaborativa entre os professores participantes de um curso de formação, e Magalhães e Celani (2005) também basearam-se em princípios vigotskyanos para criar uma relação colaborativa entre duplas de professores da rede pública num curso reflexivo de formação continuada. ${ }^{6}$

Esse tipo de relação, no entanto, não parece ser comumente encontrada entre professores e pesquisadores no meio acadêmico, nem tampouco entre professores e supervisores em escolas de ensino fundamental e médio ou institutos de ensino de línguas (GIMENEZ, 1999b; MOITA LOPES, 2000). Porém, é preciso que se reconheça que a forma tradicional de se supervisionar ou observar professores não traz grandes contribuições para o seu desenvolvimento profissional. Ao contrário, muitas vezes as atitudes avaliativas de supervisores e pesquisadores podem causar sentimentos de inferioridade e medo no professor, prejudicando sua criatividade e auto-confiança (GEBHARD, 1990b). Como bem lembra Chamberlin (2000, p. 654), abordagens tradicionais à supervisão - e à pesquisa - de professores em formação"são caracterizadas por uma diferença de poder", o que não favorece a criação de um contexto colaborativo que promova a exploração de crenças e práticas por parte dos participantes. Vale

${ }^{6}$ Embora esses dois últimos trabalhos tenham usado o conceito de scaffolding na relação entre os participantes de seus respectivos cursos, eles exemplificam a amplitude com que esta idéia tem sido recentemente aplicada 
20 Mattos - Colaboração e confiança na formação do professor de língua...

a pena, portanto, investir em uma relação mais equilibrada entre professores em formação e supervisores ou pesquisadores em busca de um maior desenvolvimento profissional para todos os participantes.

Diante do exposto, pode-se concluir que, tanto as pesquisas quanto os programas de formação de professores de LE têm, por vezes, assumido uma postura comportamentalista, ou seja, tendem a se preocupar mais com o comportamento do professor em sala de aula e com os efeitos que tal comportamento pode ter no aprendizado dos alunos, embora já haja tanto pesquisadores quanto supervisores que assumem uma postura mais simétrica e menos comportamentalista em relação a seus informantes de pesquisa e seus supervisionados. Assim, nesta pesquisa adotou-se uma postura que teve por objetivo fomentar o desenvolvimento da professora participante, segundo as sugestões dos vários autores discutidos acima. Para tanto, a pesquisa utilizou a reflexão como principalferramenta (WALLACE,1991), pois através dela oprofessor pode buscar uma auto-compreensão e se instrumentalizar para melhor lidar com seus problemas. A reflexão, portanto, constitui um instrumento emancipador e empoderador (MAGALHÃES e CELANI, 2005; MEZIROW, 1990) para o professor de LE.

Além disso, as idéias propostas por Gebhard (1990a, b) e Freeman (1990) sobre a interação entre professor e supervisor e o tipo de relação existente entre eles (GIMENEZ, 1999a, b; PICA 2000) também representam um pilar teórico significativo para os objetivos propostos. Seguindo, portanto, as sugestões desses autores, com a metodologia utilizada na pesquisa, a pesquisadora procurou adotar uma atitude não-diretiva e não-avaliativa para com a professora participante. Essa atitude permitiu que a participante assumisse um papel colaborativo na pesquisa, fornecendo informações que não poderiam ser obtidas de outra forma. A pesquisadora, por sua vez, embora não tivesse o status oficial de supervisora em sua relação com a participante ${ }^{7}$, buscou assumir o papel do participante mais experiente, na concepção de Vygotsky (apud LANTOLF \& APPEL, 1994; REGO, 1994), atuando, assim, na Zona de Desenvolvimento Proximal e fornecendo a ajuda necessária (scaffolding) para que a professora participante se sentisse segura e amparada.

'A participante, como veremos a seguir, era estagiária do Centro de Extensão da Faculdade de Letras, onde uma supervisora observava suas aulas esporadicamente, sem relação com a pesquisa aqui relatada. 


\section{A professora participante e o contexto da pesquisa}

A participante desta pesquisa foi uma professora de inglês do CENEX (Centro de Extensão) ${ }^{8}$ da Faculdade de Letras da UFMG, que lecionava no curso básico de inglês para adultos. Carolina, nome fictício por ela mesma escolhido, era na época da realização da pesquisa aluna do $8^{\circ}$ período do curso de Letras e não tinha experiência anterior de ensino. A coleta de dados foi realizada numa turma do estágio IV do Curso Básico de Inglês para Adultos, do CENEX, cuja professora era a participante.

A pesquisa utilizou entrevistas de retrospecção estimulada por gravações em vídeo das aulas da professora-participante, ou seja, as entrevistas eram realizadas durante sessões de visionamento em que a participante e a pesquisadora assistiam juntas às gravações anteriormente realizadas. Essa técnica estimula as lembranças do professor que, ao rever as imagens de suas aulas gravadas em vídeo, fornece suas interpretações sobre os eventos ocorridos (NUNAN, 1992).

Os dados foram coletados durante um mês de aula, totalizando oito aulas gravadas em vídeo e oito entrevistas de retrospecção. Após cada aula gravada, a pesquisadora e a participante se reuniam para as sessões de visionamento e entrevistas de retrospecção. Terminada a coleta de dados, as entrevistas de retrospecção foram transcritas e analisadas qualitativamente. ${ }^{9}$ Ao final do processo de gravação e visionamento das aulas, foi utilizado um questionário de avaliação final em que a professora participante refletiu sobre as entrevistas realizadas e avaliou as possíveis influências da pesquisa em sua prática de sala de aula.

\section{Colaboração e confiança: em busca do desenvolvimento profissional}

A análise dos dados aqui apresentada tem por objetivo revelar momentos de colaboração e atitude não-diretiva durante o processo de coleta de dados. Foram, assim, encontrados nos dados alguns

${ }^{8} \mathrm{O}$ CENEX oferece cursos de línguas estrangeiras para alunos, professores e funcionários da UFMG e para a comunidade em geral. Os professores desses cursos são, preferencialmente, os alunos dos cursos de letras da FALE (Faculdade de Letras), que ali cumprem seu estágio curricular.

${ }^{9} \mathrm{Para}$ conhecer outros resultados dessa pesquisa, ver Mattos (2000, 2002a e b, e 2003). 
trechos das entrevistas que revelam momentos de colaboração entre a pesquisadora e a professora participante. Esses trechos mostram como a pesquisadora e a professora participante construíram entre si uma relação de confiança, permitindo que a pesquisadora atuasse como parceiro mais experiente, ou seja, atuasse na ZPD, realizando o scaffolding (ou aindaime) necessário para que a professora participante evoluísse na sua profissão. Esses trechos demonstram, portanto, que a escolha pela atitude não-diretiva parece ter contribuído para o processo de reflexão da participante, levando-a a um amadurecimento profissional.

Os trechos analisados revelaram três tipos de intervenção da pesquisadora, durante o processo de coleta de dados: perguntas de apoio, intervenções apreciativas, e comentários e sugestões. A seguir, são exemplificados e comentados cada um destes três tipos de intervenção da pesquisadora.

\section{Perguntas de Apoio}

As perguntas de apoio tinham por objetivo estender o pensamento da professora participante ou provocar novas reflexões. Os excertos ${ }^{10}$ abaixo, extraídos das entrevistas de retrospecção realizadas durante as sessões de visionamento, exemplificam este tipo de intervenção da pesquisadora:

PE - Já que você falou que está achando a aula um pouco lenta, né: se você estivesse na posição de aluna, o que você estaria achando dessa aula, você acha que estaria gostando daquele estilo de professor, você acha que ia querer que o professor mudasse?... Se você estivesse na posição do aluno, o que você acha que estaria pensando?

(Primeira Entrevista - p. 5)

Como se vê, no trecho acima, a pesquisadora aproveita-se de um comentário anteriormente feito pela professora participante sobre o ritmo da aula para indagar sobre o seu estilo de aprender. A pesquisadora, no entanto, não emite sua opinião sobre o assunto, pelo menos não explicitamente, embora ofereça algumas opções. Da

\footnotetext{
${ }^{10}$ Convenções Adotadas nas Transcrições: PP $\rightarrow$ Professora Participante; PE $\rightarrow$ Pesquisadora; $\ldots \rightarrow$ Pausa breve ou hesitação; [ ] $\rightarrow$ Comentários da pesquisadora, inseridos durante a transcrição dos dados ou durante a seleção e apresentação dos exemplos para facilitar a compreensão; J e MF $\rightarrow$ Alunas do curso, cujos nomes foram apagados, mantendo-se apenas as iniciais, para preservar seu anonimato.
} 
mesma forma, nos trechos citados a seguir, a pesquisadora utilizase de perguntas de apoio para tentar provocar novas reflexões da participante. Nesses trechos, a pesquisadora e a participante conversam sobre a forma como a professora participante normalmente faz perguntas às alunas do curso. $O$ ponto em questão é a constatação de que as alunas não participam ativamente da aula. As perguntas de apoio, apesar de formuladas de forma direta e focalizada, procuram não direcionar o pensamento da participante.

PE - Você disse que já pensou sobre a sua maneira de fazer perguntas. $\mathrm{O}$ que você achou?

(Primeira Entrevista)

PE - Nesta parte do vocabulário, por exemplo, você foi dando várias palavras novas. Então você pergunta aqui na letra " $c$ ", "sobre essa moça da foto " $c$ " [referindo-se à página do livro didático utilizado],"o que vocês podem falar sobre ela?"Aí, elas só falam do"dark, short hair", né. E, depois você continua dando o resto da descrição. Por que você acha que acontece isso?

PP - Por causa ... acho que do nível delas, esse negócio de adjetivo pra descrever pessoas ... é sempre, fica só no cabelo, ou no olho e pronto, então ...

\section{(Primeira Entrevista)}

Com o desenrolar da entrevista, a professora participante volta a falar sobre o problema da pouca participação das alunas na aula. No excerto abaixo, a pesquisadora novamente usa perguntas de apoio para ajudar a participante a avançar em sua reflexão, embora evite claramente fornecer sua própria opinião.

PP - Agora, também, esse negócio dela [a aluna J] não responder, é outra coisa também que eu já pensei, e agora com o vídeo aqui eu lembrei, que eu fico muito ... é ... virada pras duas lá [as duas alunas melhores]. ... Eu fico só virada pra lá.

$\mathrm{PE}-\mathrm{E}$ por que você acha que isso acontece?

(Primeira Entrevista)

Nesse trecho, pode-se ver que a professora participante começou a perceber, com a ajuda do vídeo e das perguntas de apoio da pesquisadora, que sua postura na sala de aula não favorece a participação das alunas mais tímidas ou de menor comando da língua alvo. $\mathrm{O}$ excerto a seguir, retirado da terceira entrevista de retrospeç̧ão, revela o momento em que a pesquisadora percebe 
24 Mattos - Colaboração e confiança na formação do professor de língua...

que a atitude da participante começou a mudar. Embora em sua fala ela chame a atenção da participante para o fato de que algo está diferente, ela não diz o que é. A repetição do trecho do vídeo ajuda a participante a perceber a mudança em sua própria maneira de ensinar.

PE - Mas, você notou alguma coisa diferente? Você falou que a MF já falou mais, né, que você já puxou um pouquinho mais por ela. Mas eu estou notando outra coisa aí nessa cena final, depois que a J chegou principalmente. Você quer ver um pouquinho? [referindo-se à gravação em vídeo]

\section{[Repetição do trecho gravado em vídeo]}

PP - É, não, é que eu estou procurando... O que eu notei é que eu estou procurando mais olhar e o jeito do corpo mesmo, dar mais atenção também pro lado de cá, que eu não estava dando muita, à J, e à sala toda, elas todas, né, às cinco, todas.

(Terceira Entrevista)

Como é possível perceber, portanto, a partir dos trechos citados, a pesquisadora faz intenso uso de perguntas de apoio durante as entrevistas de retrospecção. Fica claro, porém, que estas perguntas têm o único objetivo de promover a reflexão da professora participante e ajudá-la a melhor compreender as várias situações discutidas.

\section{Intervenções apreciativas}

Este tipo de intervenção difere das perguntas de apoio principalmente pelo fato de que nelas a pesquisadora emite uma opinião sobre o assunto em questão. Esta opinião pode ser negativa ou positiva. Contudo, como veremos nos exemplos a seguir, a opinião da pesquisadora é sempre emitida com extremo cuidado para não prejudicar a relação de confiança a ser construída com a participante da pesquisa. No excerto abaixo, a pesquisadora se prepara para fazer uma pergunta sobre o uso do quadro negro pela professora participante. Esta interrompe dizendo que já havia percebido que as informações lançadas no quadro estão desorganizadas. A pesquisadora, embora concorde que naquele momento específico o quadro pareça mesmo desorganizado, relembra outros momentos já observados em que a professora participante utilizou o quadro de forma bastante organizada, fazendo assim uma avaliação positiva da atuação da participante em sala de aula. 
PE - Sobre o uso do quadro...

PP - Que eu percebi agora que é desorganizado, né?

PE-Não, mas nãovamos nos importar com a desorganização... Porque eu me lembro que teve uma aula que você deu o uso do "ing"... eu lembro que você colocou as regrinhas bonitinho no quadro, 1, 2, 3, tudo organizadinho. Quer dizer, então não é sempre que você é desorganizada. Dependendo do momento você é organizada.

(Primeira Entrevista)

Oexcertoabaixoretomaa discussãojáapresentadaanteriormente. Nele a pesquisadora e a participante voltam a discutir a questão da participação das alunas na aula. A pesquisadora ressalta para a participante que ela precisa mudar sua atuação na sala de aula para conseguir maior participação de suas alunas. Contudo, é a professora participante quem chega à conclusão final sobre qual o real problema que ela está vivenciando em sua sala de aula.

PE - ...Quer dizer, quem é melhor vai melhorando, quem é pior vai piorando.

PP - É, é.

PE - Isso é uma coisa para você pensar e ver como você pode mudar daqui pra frente. Você está vendo que... não é que não esteja funcionando. Está funcionando...

PP-É.

PE - Mas só está funcionando pra metade da turma.

PP - É, eu tenho que puxar mais a atenção das outras.

PE - Não, acho que ... elas estão prestando atenção. Atenção elas têm.

PP - É. O negócio é elas participarem mais ativamente, né?

PE - Uhum. Isso.

(Primeira Entrevista)

No excerto abaixo, mais uma vez a pesquisadora emite sua opinião sobre um evento ocorrido durante a aula da professora participante. Embora nesse caso a pesquisadora faça uma avaliação negativa da atuação da participante, deixando claro que ela precisa esclarecer as instruções para as alunas, isso é feito de forma indireta, com o objetivo de amenizar a avaliação feita. $\mathrm{O}$ uso repetido da 
26 Mattos - Colaboração e confiança na formação do professor de língua...

palavra talvez e a inserção da frase a impressão que dá deixam clara esta intenção da pesquisadora.

PE - Talvez, o que tenha dificultado pra elas [as alunas], a impressão que dá, é que elas não sabiam muito bem o que elas tinham que fazer. Elas não sabiam o que estava sendo esperado delas. Talvez isso tenha prejudicado a participação também."

(Quarta entrevista)

Assim, vemos que, apesar de a pesquisadora ter, algumas vezes, emitido opiniões próprias e feito avaliações sobre a atuação da professora participante, isto sempre foi feito com muito cuidado, procurando não minar a relação de confiança de que ambas desfrutavam.

\section{Comentários e Sugestões}

Este último tipo de intervenção, na verdade, agrupa dois subtipos: os comentários e as sugestões feitas pela pesquisadora. Esse agrupamento foi feito porque, muitas vezes, as sugestões vinham acompanhadas de comentários mais gerais ou vice-versa. No excerto abaixo, por exemplo, a pesquisadora sugere que a participante tente pensar no estilo de aprendizagem de suas alunas durante a preparação das aulas, e comenta que ela já consegue fazer isso porque já conhece as alunas, devido aos dois meses de aula já transcorridos.

PE - Então, aí vem a dica da pesquisadora [risos] - isso é uma coisa que eu queria evitar, mas eu acho que pode te ajudar - Quando você está preparando essa aula... eu acho que você podia pensar no que o livro está propondo, no que o teacher's guide está propondo para determinada atividade, e tentar pensar em como são as suas alunas, porque você já tem quase dois meses de aula...

PP-É.

PE - ...você já conhece elas um pouquinho. Então... você pode tentar ver como que a maneira como que o livro está propondo a atividade, pode te- quer dizer, se você fizer alguma adaptação, de repente você pode ter um retorno melhor delas.

(Primeira entrevista)

É possível perceber, no exemplo acima, que, mesmo fazendo sugestões para a participante, a pesquisadora utiliza-se de 
um linguajar reticente e indireto, como demonstra o uso das expressões quer dizer e de repente, para tentar diminuir o impacto de suas observações sobre a relação de cooperação entre as duas. O mesmo acontece no excerto abaixo, onde a pesquisadora volta a usar a expressão de repente, ao sugerir que a participante tente fazer atividades de listening usando vídeos, ao invés de apenas fitas cassette.

PE - Você não acha que seria interessante, por exemplo, você tem uma aluna - você já mencionou duas vezes - que ela não gosta de listening. Mas de repente, ela gosta mais desse outro tipo de listening [com vídeo]. $\mathrm{E}$ as outras também, não sei. Acho que seria interessante você buscar esse tipo de feedback delas. Saber o que elas acharam, né, como foi a reação, o que elas pensaram. Porque ... eu acho que elas não devem ter visto isso de outras vezes.

(Quinta entrevista)

Os vários excertos acima procuram mostrar, assim, como a pesquisadora conseguiu construir, através de uma postura nãodiretiva em relação à professora participante, uma relação de confiança que lhe permitiu maior acesso às reflexões da participante, ao mesmo tempo em que ajudou a fomentar o seu desenvolvimento profissional. Em suas respostas a algumas das perguntas do questionário de avaliação final, a professora participante fez referência a dois pontos relevantes para a discussão apresentada acima: a influência da pesquisa na sua maneira de ensinar e a postura da pesquisadora. Os trechos abaixo, extraídos de suas respostas ao questionário de avaliação final, se referem ao primeiro ponto:

Pergunta 4-O que você acha que aprendeu a partir desta experiência?

"Aprendi melhor como observar e refletir sobre meu ensino, pois eu mesma deveria abranger diferentes aspectos práticos e/ou teóricos da aula, na medida em que justificava minhas atitudes."

Pergunta 6 - Que efeito você acha que refletir sobre suas aulas teve sobre o seu processo de aprender a ensinar?

“Também sobre meu processo de aprender a ensinar, esta experiência teve um efeito positivo. Constatei como é útil refletir sobre minhas aulas para poder ensinar melhor, porque posso perceber o que é mais eficaz e produtivo no ensino/ aprendizagem. Acredito, ainda, que esta experiência de auto- 
28 Mattos - Colaboração e confiança na formação do professor de língua...

observação acelera o bom desenvolvimento do processo de aprender a ensinar."

Pergunta 7 - Compare você hoje com você mesma antes da pesquisa. Você vê alguma mudança?

"Houve muita mudança. Sou mais consciente e segura do que faço, porque tenho a possibilidade de checar, confirmar, ou tirar qualquer dúvida com relação ao que aconteceu na sala de aula, no momento mais tranqüilo do que o da aula, que é o de auto-observação. E, definitivamente, tenho o que não tinha anteriormente:'a ferramenta' (a auto-observação) para fazer com que possa melhorar cada vez mais minha maneira de ensinar."

O segundo ponto, ou seja, a postura adotada pela pesquisadora durante as sessões de visionamento e as entrevistas de retrospecção, foi abordado em sua resposta à pergunta 2 :

Pergunta 2 - O que você considerou positivo ou negativo sobre esta experiência?

"Os aspectos positivos dessa experiência foram o de adquirir o hábito de auto-observação e reflexão de minhas aulas; o de melhorar meu desempenho como professora; o de participar de um processo de pesquisa; e o de 'trabalhar' com você que é uma pessoa incentivadora e compreensiva."

Como é possível notar, em várias de suas respostas ${ }^{11}$, a professora participante mencionou a importância de sua participação nesta pesquisa e teceu comentários sobre a influência da metodologia utilizada no seu desenvolvimento profissional. Além disso, ela também fez menção, ainda que breve, à postura adotada pela pesquisadora, o que revela, na voz da própria participante, o quanto esta postura foi importante para o bom desenvolvimento da sua relação com a pesquisadora, assim como para os resultados da pesquisa.

\section{Considerações Finais}

Este trabalho ressalta o papel da auto-observação como importante ferramenta para a conscientização e o desenvolvimento do professor de LE, especialmente quando baseada numa relação de

"As demais perguntas e respostas do questionário de avaliação final não foram abordadas por serem irrelevantes para os objetivos deste trabalho. 
confiança com um parceiro colaborativo. Essa relação de confiança, como visto, permite uma maior conscientização sobre a tarefa de ensinar por parte de ambos os participantes (CHAMBERLIN, 2000; Gebhard, 1990b). Contudo, é papel do supervisor/pesquisador, na qualidade de membro mais experiente da interação, "conquistar a confiança do professor em formação e criar um ambiente que cultive a reflexão, a exploração e a mudança" (CHAMBERLIN, 2000, p. 656). Esta é, sem dúvida, uma tarefa difícil para supervisores e pesquisadores ainda acostumados a abordagens mais tradicionais e uma tarefa que requer maior atenção para a relação entre os participantes. Já que, como visto, esta almejada relação de confiança deve ser construída entre os participantes, é preciso focalizar, então, os fatores que contribuem para sua construção. Este trabalho é, assim, um pequeno exemplo de como esta relação foi construída entre uma pesquisadora e uma professora de inglês em formação, objetivando o desenvolvimento profissional da participante.

\section{Referências}

ALLWRIGHT, D.; BAILEY, K. Focus on the language classroom. New York: Cambridge University Press, 1991. 250 p.

ALMEIDA FILHO, J. C. P. Dimensões comunicativas no ensino de línguas. Campinas: Pontes, $1993.75 \mathrm{p}$.

Tendências na formação continuada do professor de língua estrangeira. APLIEMGE: Ensino \& Pesquisa, n. 1, p. 29-41, 1997.

(Org.) O professor de língua estrangeira em formação. Campinas: Pontes, 1999. 184 p.

BAGHIN, D. C. M.; ALVARENGA, M. B. A auto-observação do professor de língua estrangeira: instrumento para reflexão e mudanças. APLIEMGE: Ensino \& Pesquisa, n. 1, p. 53-8, 1997.

CELANI, M.A.A. (org.). Professores e formadores em mudança. Campinas, SP: Mercado de Letras, 2003.

CHAMBERLIN, C. TESL Degree Candidates' perceptions of trust in supervisors. TESOL Quarterly, v. 34, n. 4, p. 653-673, 2000.

FREEMAN, D. Teacher training, development, and decision making: a model of teaching and related strategies for language teacher education. TESOL Quarterly, v. 23, n. 1, p. 27-45, 1989.

Intervening in practice teaching. In: RICHARDS, J. C.; 
NUNAN, D. (Ed.) Second language teacher education. New York: Cambridge University Press, 1990. p. 103-117.

. (a) The "unstudied problem": research on teacher learning in language teaching. In: FREEMAN, D.; RICHARDS, J. (Ed.) Teacher learning in language teaching. New York: Cambridge University Press, 1996. p. 351-378.

(b) Redefining the relationship between research and what teachers know. In: BAILEY, K.; NUNAN, D. (Ed.) Voices from the language classroom. New York: Cambridge University Press, 1996. p. 88-115.

The hidden side of the work: teacher knowledge and learning to teach. Language Téaching, v. 35, p. 1-13, 2002.

FREIRE, M. M.; ABRAHÃO, M. H.V.; BARCELOS, A. M. F. (Org.) Lingüística Aplicada e contemporaneidade. São Paulo e Campinas: Pontes / ALAB, 2005. $352 \mathrm{p}$.

GEBHARD, J. G. (a) Interaction in teaching practicum. In: RICHARDS, J. C.; NUNAN, D. (Ed.) Second language teacher education. New York: Cambridge University Press, 1990. p. 118-131.

(b) Models of supervision: choices. In: RICHARDS, J. C.; NUNAN, D. (Ed.) Second language teacher education. New York: Cambridge University Press, 1990. p. 156-166.

GIMENEZ, T. Learners becoming teachers: an exploratory study of beliefs held by prospective and practising EFL teachers in Brazil. 1994. 346 f. Tese (Doutorado em Lingüística) - Department of Linguistics and Modern English Language, Lancaster University, Lancaster, 1994.

(Org.). (a) Os sentidos do projeto NAP: ensino de línguas e formação continuada do professor. Londrina: UEL, 1999. 88 p.

. (b) Uma crítica da relação universidade/ensino fundamental e médio. In: GIMENEZ, T. (Org.). Os sentidos do projeto NAP: ensino de línguas e formação continuada do professor. Londrina: UEL, 1999. p. 11-17.

LANTOLF, J. P.; APPEL, G. Theoretical framework: an introduction to Vygotskian approaches to second language research. In: LANTOLF, J. P. ; APPEL, G. (Ed.). Vygotskian Approaches to Second Language Research. Norwood, NJ: Ablex Publishing Corporation, 1994. p. 1-32.

MATTOS, A. M. A. Percepções de uma professora de inglês sobre sua sala de aula: uma visão êmica. 2000. 149 f. Dissertação (Mestrado em Letras) - Faculdade de Letras, Universidade Federal de Minas Gerais, Belo Horizonte, 2000.

(a) Percepções sobre a sala de aula de língua estrangeira: uma visão global e êmica. Revista de Estudos da Linguagem, Belo Horizonte, v. 10, n. 1, p.109-138, jan.jun. 2002. 
(b) O professor no espelho: conscientização e mudança pela auto-observação. Revista Brasileira de Lingüística Aplicada, Belo Horizonte, v.2, n. 1, p. 121-155, 2002.

. Fatores que influenciam a sala de aula de língua estrangeira: um relato pessoal. Letras $\mathcal{E}$ Letras, Uberlândia, v.19, n. 2, p. 21-39, jul.dez. 2003.

MEZIROW, J. (Ed.) Fostering critical reflection in adulthood: a guide to transformative and emancipatory learning. San Francisco: Jossey-Bass, 1990. 388 p.

MOITA LOPES, L. P. Oficina de Lingüística Aplicada. Campinas: Mercado das Letras, 1996. 190 p.

. Co-construção do discurso em sala de aula: alinhamento a contextos mentais gerados pela professora. In: FORTKAMP, M. B. M.; TOMITCH, L. M. B. (Org.) Aspectos da Lingüística Aplicada: estudos em homenagem ao Professor Hilário Inácio Bohn. Florianópolis: Insular, 2000.

MULLOCK, B. The pedagogical knowledge base of four TESOL teachers. The Modern Language Journal, v. 90, n. 1, p. 48-66, 2006.

NUNAN, D. Understanding language classrooms: a guide for teacher initiated action. Cambridge: Prentice Hall, 1989. 183 p.

NYIKOS, M.; HASHIMOTO, R. Constructivist theory applied to collaborative learning in teacher education: in search of ZPD. The Modern Language Journal, v. 81, n. 4, p. 506-17, 1997.

PICA, T. A. relação professor/pesquisador: múltiplas perspectivas e possibilidades. Linguagem \& Ensino, Pelotas, v. 3, n. 1, p. 55-88, jan. 2000.

REGO, T.C. Vygotsky: uma perspectiva histórico-cultural da educação. Petrópolis: Vozes, 1994. 138 p.

REIS, S. Os sentidos de uma proposta de ação e reflexão no ensino de língua inglesa em escolas públicas. In: GIMENEZ, T. (Org.). Os sentidos do projeto $N A P$ : ensino de línguas e formação continuada do professor. Londrina: UEL, 1999. p. 33-40.

RICHARDS, J. C. The dilemma of teacher education in second language teaching. In: RICHARDS, J. C.; NUNAN, D. (Ed.) Second language teacher education. New York: Cambridge University Press, 1990. p. 3-15.

WALLACE, M. J. Training foreign language teachers: a reflective approach. Glasgow: Cambridge University Press, 1991.180 p. 